\title{
Epidemiological and clinical status of patients with scorpion sting: emergency department of Sina hospital in Tabriz-Iran
}

\author{
Kavous Shahsavarinia' ${ }^{1}$ Ali Taghizadieh ${ }^{2}$, Amir Ghaffarzad ${ }^{1}$, Amin Shariati $^{3}$, Farzad Rahmani ${ }^{*}$ \\ 'Emergency Medicine Research Team, Tabriz University of Medical Sciences, Tabriz, Iran \\ ${ }^{2}$ Tuberculosis and Lung Disease Research Center, Tabriz University of Medical Sciences, Tabriz, Iran \\ ${ }^{3}$ Students' Research Committee, Tabriz University of Medical Sciences, Tabriz, Iran \\ ${ }^{4}$ Road Traffic Injury Research Center, Tabriz University of Medical Sciences, Tabriz, Iran
}

\author{
Received: 27 January 2016 \\ Accepted: 9 April 2016 \\ Published online: 13 May 2016 \\ *Corresponding author: Farzad \\ Rahmani MD, Emergency Medicine \\ Department, Sina Medical Research \\ and Training Hospital, Tabriz \\ University of Medical Sciences, Tabriz, \\ Iran. Tel: 00984135498322, Fax: \\ 00984135412151,Email: Rahmanif@ \\ tbzmed.ac.ir \\ Competing interests: The authors \\ declare that there are no conflict of \\ interest. \\ Funding information: None. \\ Citation: Shahsavarinia K, Taghizadieh \\ A, Ghaffarzad A, Shariati A, Rahmani \\ F. Epidemiological and clinical \\ status of patients with scorpion \\ sting: emergency department of \\ Sina hospital in Tabriz-Iran. Journal \\ of Emergency Practice and Trauma \\ 2017; 3(1): 18-21. doi: 10.15171/ \\ jept.2017.08.
}

\begin{abstract}
Objective: Scorpion is one of the world's most venomous arthropods and every year many people are bitten by it. In Iran, scorpion sting is a common health issue. The aim of this study was to evaluate the epidemiological and clinical status of patients with scorpion sting in the emergency department of Sina hospital in 2014.

Methods: In this descriptive cross-sectional study, all patients with a history of scorpion sting during 2014 in the emergency department of Sina hospital in Tabriz entered the study. Required information such as sex, age, location and time of the sting, the patient's symptoms, etc were extracted from the medical records. These findings were analyzed using SPSS version 15 .

Results: Based on our results, $47.2 \%$ of patients were male. The mean \pm SD of their age was $35.63 \pm 18.87$. Of 176 patients, $83 \%$ lived in urban areas, $87 \%$ of scorpion sting cases occurred in houses, and $81.3 \%$ of stings were done by yellow scorpion. Most of the bites were in upper extremities (47.2\%). In evaluation of symptoms and signs of patients, $89.8 \%$ had pain, $48.8 \%$ had local erythema and redness, $21 \%$ had inflation of sting position and $0.6 \%$ had pulmonary symptoms.

Conclusion: Scorpion stings are more common in young people as they are more active. Scorpion stings occur more frequently during the night and in the summer. In our study, most of scorpion stings occurred in houses.

Keywords: Epidemiology, Scorpions, Bites and Stings, Arthropods
\end{abstract}

\section{Introduction}

Scorpions are invertebrate animals which are part of arthropods family and have a worldwide distribution $(1,2)$. Every year, hundreds of thousands of scorpion stings occur in the world. Iran after Mexico and Colombia has a significant prevalence of scorpion stings in the world $(3,4)$. According to the type of climate and weather, Iran is very rich in arthropods species, especially scorpions. Iran is among the countries that has a lot of scorpions, particularly dangerous species $(5,6)$. Although deaths from stings occur in all regions of the country, about $75 \%$ of deaths occur in Khuzestan, Sistan and Baluchestan, Kerman and Hormozgan (7). Studies conducted in Iran shows that scorpions in Iran are from 3 families of Buthidae, Hemi Scorpid and Scorpionidae $(8,9)$.

Scorpion venom is a colorless and transparent liquid containing neurotoxin, hemotoxin and cardiotoxin. Enzymes include listinaz, hyaluronidase, phospholipase, and proteinase may ease the impact of venom (10). Clinical symptoms are different due to various scorpion species and different mechanisms of toxins and may include increased irritability, restlessness, increased body temperature, increased respiratory rate, shortness of breath, increased or decreased heart rate, sweating, nausea and vomiting, swallowing disorders, difficulty in speaking, seizures, and coma. Common symptoms of scorpion stings include dilated pupils and intermittent eye movements, excessive secretion of saliva and dysphagia, and finally agitation $(7,11,12)$.

According to multiple reported cases of scorpion stings in East Azarbaijan province and especially the city of Tabriz, we decided to investigate the epidemiological status of patients with scorpion sting in Tabriz city and introduced approaches toward the prevention of the sting, timely 
treatment and prevention of deaths from it.

\section{Methods}

This descriptive cross-sectional study was conducted in the emergency department of Sina hospital (a poisoning referral center) in Tabriz University of Medical Sciences in 2014. Information of all patients who were stung by scorpion and admitted or referred to the emergency room in Sina hospital was investigated (13). Inclusion criteria encompassed all patients who referred to the emergency department with complaints of scorpion stings. Incomplete information in the records was considered as the exclusion criterion. In order to collect data, a researcher-made checklist including study variables was prepared. Expert opinion was used to determine the validity of the questionnaire (face validity and content validity methods). In order to obtain the reliability of the checklist, Cronbach alpha test was used $(\alpha=0.8)$. Referring to the archives of the emergency department in Sina hospital, the researchers studied the records of all patients meeting the inclusion criteria and extracted the data based on the required information. A total of 189 patients were chosen, 9 cases were excluded from the study due to suspected scorpion sting or other animals or insects. Also, 4 cases were excluded due to the incomplete data in the records and a total of 176 cases were studied. The studied variables in this study included age, sex, occupation, education level, place of residence, location of sting, previous medical history, scorpion color, sting time, the anatomical location of the sting, the patient's clinical symptoms at the time of admission, history of scorpion sting and patient outcomes. Data were analyzed using SPSS software version 15 . To describe the data, descriptive statistics (frequency, percentage, mean and standard deviation) were used. In order to compare qualitative data, chi-square test was used. $P$ value less than 0.05 was considered as significant.

\section{Results}

In this study, 176 patients with complaints of scorpion stings referring to the emergency department of Sina hospital were studied. The mean \pm SD of patients' age was $35.63 \pm 18.87$. The age range of 20 -29 years was the most frequent $(29.5 \%)$ in patients (Figure 1). Eightythree $(47.2 \%)$ patients were male and $146(83 \%)$ patients were in urban areas. Of the total number of stings, 153 patients $(87 \%)$ suffered from scorpion stings inside the house. Fifty-seven (32.4\%) patients were stung in spring, 109 patients $(61.9 \%)$ in summer, $5(2.8 \%)$ in autumn and 5 (2.8\%) in winter. The highest prevalence of scorpion sting occurred in August (49 patients) and the lowest prevalence occurred in January/December (0 patient).

In terms of anatomical location of the sting, 83 (47.2\%) stings were in the upper extremities, $72(40.9 \%)$ in the lower extremities, 7 (4\%) in head and neck and $9(1 / 5 \%)$ in other parts of the body. Three patients (1.7\%) were stung in the lower and upper extremities, $1(0.6 \%)$ in the upper extremity, head and neck, and $1(0.6 \%)$ in lower extremities and the trunk. Regarding the time of sting, 47 patients
(26.6\%) were stung between $8 \mathrm{AM}$ and $4 \mathrm{PM}, 47$ patients (26.6\%) between 4 PM and 12 AM and 82 patients (46.6\%) between $12 \mathrm{PM}$ and 8 AM. Majority of patients (171 patients) had no previous history of sting.

In terms of clinical signs and symptoms, 158 patients $(89.8 \%)$ had pain at sting place, $86(48.8 \%)$ had erythema and redness, and 37 patients (21\%) had topical swelling. Three patients $(1.7 \%)$ had cellulitis and 1 patient $(0.6 \%)$ had pulmonary symptoms. Neurological, hematologic and renal symptoms/signs were not found in these patients. Among all patients, only 5 patients $(2.8 \%)$ were hospitalized and other patients were discharged from the emergency department after treatment. Concerning the type of scorpion, only the color of scorpions was listed in the records. In this regard, 143 patients were stung by yellow scorpion, 17 by black and the color of the scorpion was not mentioned in 16 cases.

With regard to the scorpion color and the symptoms, scorpion color had no significant relationship with pain $(P=0.18)$ and symptoms of erythema and topical redness $(P=0.13)$. Swelling at the sting place was significantly higher in cases who were stung by black scorpion $(P=0.01)$. Regarding the scorpion color and hospitalization among 143 stings by yellow scorpion, 1 patient (0.69\%) with symptoms of pain, redness and swelling at the sting place required hospitalization. Among 17 cases of stings by black scorpion, 3 patients (17.64\%) were hospitalized. One case who was stung by black scorpion needed intubation and hospitalization in intensive care unit due to severe respiratory distress.

Table 1 shows the correlation between the time of sting and the time the patients were visited in the emergency department. As the time between stings and referring to the emergency department is decreased, symptoms such as pain and redness in the sting place will be more. There

Table 1. The relationship between the duration of the sting and the patient's referral to the center and the emergence of symptoms

\begin{tabular}{lccc}
\hline Signs/symptoms & $\begin{array}{c}\text { Symptomatic } \\
\text { patients (hour) }\end{array}$ & $\begin{array}{c}\text { Asymptomatic } \\
\text { patients (hour) }\end{array}$ & P value \\
\hline Pain & 1.18 & 3.3 & 0.001 \\
Redness & 1.2 & 1.6 & 0.031 \\
Swelling & 1.3 & 1.6 & 0.37 \\
\hline
\end{tabular}

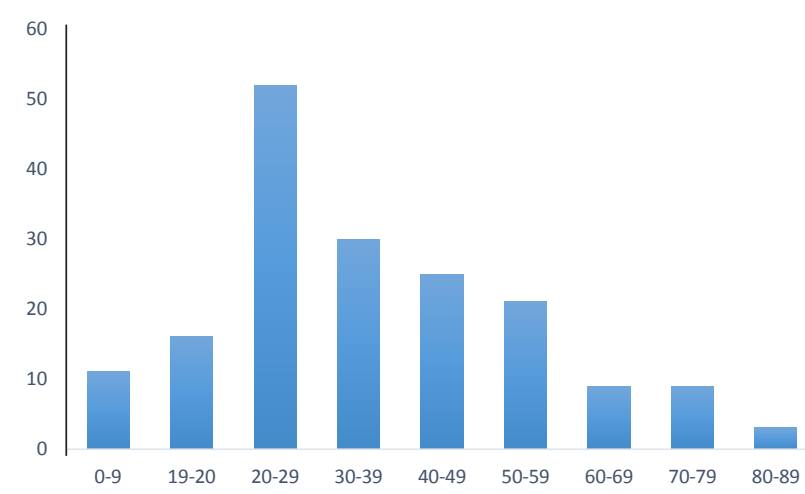

Figure 1. Distribution of patients by age ranges. 
was not any significant statistical difference between swelling of sting site and the time that patients were referred to the emergency department after the scorpion sting. The hospitalization in cases who were stung by black scorpions was significantly higher than yellow scorpions $(P=0.004)$. No death was reported in all the patients.

\section{Discussion}

In this study, 176 patients with scorpion stings were investigated. In most cases, stings by yellow scorpions were done inside the house. Upper extremities were the most involved parts. Most symptomatic signs by stings were pain in the sting place. The average age of the patients in our study was 35.6 and the age range of 20-29 years had the highest frequency.

Several studies have been done on the scorpions. In the study of Kasiri et al on 1067 patients with scorpion stings in south-western Iran, it was found that the highest incidence of scorpion stings was in August and lower organs were the largest anatomic area stung. The prevalence of scorpion stings has been reported as 5.6 per 1000 of the population (14). In the study of Cesaretli et al on 930 patients with scorpion stings in Turkey, it was identified that the frequency of the age group 20-29 years old was higher among patients and $33 \%$ of patients were treated with anti-venom (15). In a study conducted by Mohseni et al in southwestern Iran, Rāmhormoz, 179 patients with scorpion stings were examined where females had the highest frequency among patients, extremities were the most anatomic place of the stings and the frequency of stings was higher in May to August (16). In a national survey by Rafizadeh et al in 2009, the age group of 15-24 years had the highest scorpion stings (17). Gheshlaghi et al studied 147 cases of scorpion stings during the years 2007 to 2009 and reported that the age range of 20-30 years was the most common range (18). In the study of Pardal et al in Brazil during 2000, the average age of patients with scorpion stings was 33.6 (19). In a study in Texas America by Forrester and Stanley, $67.3 \%$ of people were over 19 years (20). In numerous studies conducted, the majority of stings happened during night as scorpions were more active at night $(11,12)$. Also in our study, the scorpion stings in the time range of $12 \mathrm{PM}$ to $8 \mathrm{Am}$ had the highest frequency $(46.6 \%)$. In most studies, like our study, topical symptoms like pain and swelling had the most prevalence in patients $(15,19,21)$.

The frequency of scorpion stings in terms of sex in the studies done in different regions is different. This difference can be justified due to environmental issues, scorpion types, activity and occupation of people $(21,22)$. The color of the scorpion in most reported cases was yellow $(14,16)$ which is consistent with our findings.

According to conducted studies as well as the results obtained in our research, most of the people who were stung were young. This justifies more research in this age range and the higher possibility of facing scorpion. In our study, more cases were stung in urban areas $(83 \%)$ than rural areas. This can be due to the differences in patients' access to health centers in rural areas. The people with low intensity of symptoms who live in the rural area did not referred to our hospital and treated in local clinics.

As mentioned, the scorpion sting is one of the health problems in the country and must be considered more due to its pain and complications. By identifying groups of people at risk, the season and time of the sting, its clinical signs and association with other variables, we can significantly determine and promote scorpion stings prevention programs in the province and the city of Tabriz. The limitations of our study include its retrospective and descriptive type. Based on the available information, there were no names and types of scorpions in the case of patients.

\section{Conclusion}

According to the findings of the current study and comparisons made with other studies, the scorpion stings in the province and the city of Tabriz are considerable. We can educate and inform people through media or publications to prevent scorpion stings and their annoying and sometimes dangerous complications. Considering the fact that in the recent study, most of scorpion stings happened indoors, solutions such as blocking seams, cracks and holes in walls of houses and buildings and the use of an appropriate bed while sleeping will help to prevent scorpion stings. It is also suggested to conduct a biological study in the future to determine the common species of scorpions and their abundance in the province.

\section{Acknowledgments}

Authors are grateful to all the health-providing personnel of the emergency department of Sina hospital and patients who participated in the study. This article was written based on a dataset of MD thesis, registered in Tabriz University of Medical Sciences.

\section{Ethical issues}

This study has confirmed by ethical committee of Tabriz University Medical of Science.

\section{Authors' contributions}

All authors read and approved the manuscript. KS, AT, and AS performed the data collection, writing, critical revision and drafting of the manuscript. FR and AG undertook the major parts of the study design and performed the statistical analysis, data analysis and data interpretation.

\section{References}

1. Rahmani F, Banan Khojasteh SM, Ebrahimi Bakhtavar H, Rahmani F, Shahsavari Nia K, Faridaalaee G. Poisonous spiders: bites, symptoms, and treatment; an educational review. Emerg (tehran) 2014; 2(2): 54-8.

2. Rahmani F, Banan Khojasteh SM, Ebrahimi Bakhtavar $\mathrm{H}$, Shahsavari Nia K, Jafari Roohi A, Massoud A, et al. Identification of Widow Spider in East Azerbaijan, Iran: case series. Medical Journal of Tabriz University of Medical Sciences and Health Services 2014; 36(1): 82-6. [In Persian].

3. Dehghani R, Velaei N. Scorpion bite in Iran: review of the literature. Journal of Kashan University of Medical Sciences 
(Feyz) 2005; 9(1): 66-84. [In Persian].

4. Farnaghi F, Hassanian-Moghaddam H, Faghihi Langroodi T. Fatal poisoning and its related factors among children admitted in Loghman hospital, 1995 -2004. Pajouhandeh 2009; 13(6): 529-35. [In Persian].

5. Dehghani R, Fathi B. Scorpion sting in Iran: a review. Toxicon 2012; 60(5): 919-33. doi: 10.1016/j.toxicon.2012.06.002.

6. Vazirianzadeh B, Hossienzadeh M, Moravvej SA, Vazirianzadeh M, Mosavi SA. An epidemiological study on scorpion stings in Lordegan county, south-west of Iran. Archives of Razi Institute 2013; 68(1): 71-6.

7. Sedaghat MM, Salehi Moghadam AR, Dehghani R. Mapping the distribution of some important scorpions collected in the past five decades in Iran. J Army Univ Med Sci 2011; 9(4): 285-96.

8. Prendini L, Wheeler WC. Scorpion higher phylogeny and classification, taxonomic anarchy, and standards for peer review in online publishing. Cladistics 2005; 21(5): 446-94. doi: 10.1111/j.1096-0031.2005.00073.x.

9. Sahin C, Acar E, Beydilli H, Mert KU, Akin F, Altun I. Acute toxic myocarditis and pulmonary oedema developing from scorpion sting. Int Cardiovasc Res J 2015; 9(1): 55-9.

10. Jalalia A, Rahim F. Epidemiological review of scorpion envenomation in Iran. Iran J Pharm Res 2014; 13(3): 74356.

11. Schneir AB, Clark RF. Bites and stings. In: Tintinalli JE, ed. Tintinalli's Emergency Medicine. 7th ed. China: McGraw Hill; 2011. p. 1351-2.

12. Pipelzadeh $\mathrm{MH}$, Jalali A, Taraz M, Pourabbas R, Zaremirakabadi A. An epidemiological and a clinical study on scorpionism by the Iranian scorpion Hemiscorpius lepturus. Toxicon 2007; 50(7): 984-92. doi: 10.1016/j. toxicon.2007.07.018.

13. Eshghi M, Rahmani F, Derakhti B, Robai N, Abdollahi F, Tajoddini S. Patient satisfaction in the emergency department: a case of Sina hospital in Tabriz. Journal of Emergency Practice and Trauma 2016; 2(1): 16-20. doi: 10.15171/jept.2015.06

14. Kasiri H, Kasiri E, Behbahani R, Kasiri A. Epidemiological survey on scorpionism in Gotvand County, Southwestern Iran: an analysis of 1067 patients. Journal of Acute Disease 2014; 3(4): 314-9. doi: 10.1016/S2221-6189(14)60067-6.

15. Cesaretli Y, Ozkan O. Scorpion stings in Turkey: epidemiological and clinical aspects between the years 1995 and 2004. Rev Inst Med Trop Sao Paulo 2010; 52(4): 215-20.

16. Mohseni A, Vazirianzadeh B, Hossienzadeh M, Salehceh M, Moradi A, Moravvej SA. The roles of some scorpions, Hemiscorpius lepturus and Androctonus crassicauda, in a scorpionism focus in Ramhormorz, southwestern Iran. J Insect Sci 2013; 13: 89. doi: 10.1673/031.013.8901.

17. Rafizadeh S, Rafinejad J, Rassi Y. Epidemiology of Scorpionism in Iran during 2009. J Arthropod Borne Dis 2013; 7(1): 66-70.

18. Gheshlaghi F, Yaraghi A, Hashemi E. An epidemiological study on scorpionism in Isfahan province. Journal of Isfahan Medical School 2011; 28(114): 885-91.

19. Pardal P, Castro L, Jennings E, Pardal J, Monteiro M. Epidemiological and clinical aspects of scorpion envenomation in the region of Santarém, Pará, Brazil. Rev Soc Bras Med Trop 2003; 36(3): 349-53. doi: 10.1590/s003786822003000300006 .

20. Forrester MB, Stanley SK. Epidemiology of scorpion envenomation in Texas. Vet Hum Toxicol 2004; 46(4): 21921.

21. Abourazzak S, Achour S, Arqam L, Atmani S, Chaouki S, Semlali I, et al. Epidemiological and clinical characteristics of scorpion stings in children in Fez, Morocco. Venom Anim Toxins Incl Trop Dis 2009; 15(2): 254-67. doi: 10.1590/s1678-91992009000200008.

22. Karami Kh, Vazirianzadeh B, Mashhadi E, Hossienzadeh M, Moravvej SA. A five year epidemiologic study on scorpion stings in Ramhormoz, South-West of Iran. Pakistan J Zool 2013; 45(2): 469-74. 